Proc. Estonian Acad. Sci. Eng., 2004, 10, 2, 69-81

\title{
Model-based interpretation of intramyocardial electrograms for cardiac risk assessment and surveillance
}

\begin{abstract}
Helmut Hutten
Institute of Biomedical Engineering, University of Technology, Inffeldgasse 18, A-8010, Graz, Austria; hutten@bmt.tu-graz.ac.at

Received 8 January 2004

Abstract. Intramyocardial electrograms (IEGMs), which are acquired by using implanted devices with telemetric capability, offer a challenging potential for long-term cardiac risk assessment and surveillance. However, new approaches to the interpretation of these signals are required. Therefore, a model has been developed for the simulation of excitation spreading across the myocardium and of the subsequent contraction. It allows to analyse systematically the influence of all relevant parameters including the position of the electrode for stimulation and recording. The model can be matched to individual heart geometries, for example, taken from ultrafast CT images. This approach helps to utilize the information represented in the morphology of IEGMs for permanent cardiac risk monitoring.
\end{abstract}

Key words: intramyocardial electrograms, heart model, excitation spreading, contraction, signal analysis, parameter extraction, risk monitoring.

\section{INTRODUCTION}

\subsection{Medical and socio-economical background}

In nearly all industrialized countries the diseases of the cardiovascular system and the death cases caused by cardiovascular dysfunctions are ranking high in respective statistics. The WHO Health Data register depicts for Germany in 1999 the following causes and numbers of cases per 100000 inhabitants which have required a stationary treatment in a hospital:

$\begin{array}{lr}\text { cardiovascular system } & 3367 \text { cases } \\ \text { cardiac ischaemia } & 1035 \text { cases } \\ \text { cerebrovascular system } & 580 \text { cases }\end{array}$


Thus in total nearly 5000 cases per 100000 inhabitants have required a stay in hospital.

The total number of death cases in Germany in 2001, related with different cardiovascular dysfunctions, has been 384900 (nearly 50\% of all death cases), and can be assigned to certain ICD-10 classified disorders as published by the Statistisches Bundesamt Deutschland:

chronic cardiac ischaemia (ICD-10, 125) $9277511.2 \%$ of all death cases

acute myocardial infarction (ICD-10, 121) $652287.9 \% \quad$-,-

myocardial insufficiency (ICD-10, I 50) $567996.8 \% \quad$-”

brain stroke (ICD-10, I 64)

$406714.9 \%$

The costs for the public healthcare system caused by cardiovascular dysfunctions have been 42.6 billion DM (roughly 22 billion $€$ ) in 1998. About $75 \%$ of these costs have been spent for the treatment in hospitals. Regarding the years, which have been lost for professional working activities due to illness, the disorders of the cardiovascular system have caused $11.5 \%$ of all lost years.

Cardiac risk factors might be related with congenital defects and dysfunctions or with lifestyle misbehaviour like smoking, overweight and alcohol abuse. Some diseases which are accompanied by an enhanced cardiac risk are hypertension, diabetes and chronic hemodialysis.

\subsection{Engineering background}

Biomedical engineering aims at the analysis of physiological systems with special regard of the model-based simulation and interpretation of the system's behaviour and its most relevant variables. This computer-supported approach is increasingly recognized as another contribution to refined diagnosis and therapy management and as a supplement to the traditional medical approach that is mainly based on empirical knowledge and statistics.

The models of engineers are ranging from simple input-output models (black box models), which may have multiple inputs and outputs (e.g., Single-InputSingle-Output SISO, Multiple-Input-Single-Output MISO, Single-Input-MultipleOutput SIMO, Multiple-Input-Multiple-Output MIMO) to very complex models in which the internal structure describes the real internal structure of the physiological system with the required deepness. This deepness can go down to the level of organs, cells, or even molecules. Since the development of such complex models should consider all available and relevant $a$ priori knowledge, it requires interdisciplinary collaboration. This collaboration is one of the major challenges for biomedical engineering in the future.

In principle a model is always only a simplification of the real physiological system. Therefore each model needs careful evaluation and should be used only for the simulation of those systems for which its validity has been proved. If a model has been evaluated, it can be employed for systematical variation of certain parameters that might not be possible in the real physiological system.

Commercially are available different software platforms that allow the realization of models. Thanks to the increasing availability of high-power 
computers, the simulation of complex physiological systems is not a major technical problem any more.

Intracardiac electrograms are directly recorded from the heart, i.e., the recording electrode is in direct contact with the cardiac tissue. The electrode may be placed either in epi- or endocardial position anywhere in the heart, in the right or left ventricle or atrium. Recording can be achieved in unipolar or bipolar mode, although the unipolar mode is more common. The signal morphology of these intracardiac or intramyocardial electrograms is competely different from that of the body surface electrocardiograms. The body surface electrodes are recording the potential at different points on the body surface. This potential with its fluctuations is caused by the electrical processes in the heart, i.e., by the spreading and regression of the excitation across the myocardium. Although the heart is actually a three-dimensional potential source, those recordings, whether in the EINTHOVEN mode, the GOLDBERGER mode or the WILSON mode, etc., are simplistically interpreted as the projection of a hypothetical vector inside the heart through the conducting body tissue on the body surface. Usually by clinical interpretation the following aspects are neglected: 1) the dimensions of the thorax are individually different, 2) the medium between the source of the potential and the recording site is not homogeneous with regard to resistivity (more precisely: the complex permittivity), and 3) the heart is not at the symmetry centre of the thorax. Typical biological distortions of surface ECG recordings are caused by different displacements of the heart and the electrode due to ventilation and movement of the heart under contraction and by the changing resistivity of the medium between the heart and the recording site due to the respiratory-dependent air filling of the alveoli. Another problem is that recording with surface electrodes is not applicable for permanent and continuous surveillance.

With regard to these difficulties, the recording of intramyocardial electrograms may offer some advantages. The electrodes are fixed in the myocardial tissue. Thus they are moving together with the surrounding tissue during contraction and together with the heart during ventilation. Using electrodes in combination with an implant that is provided with some intelligent features and telemetric capability, the permanent and continuous surveillance of the patients might be possible without inconvenience for the patient. If the implant is additionally provided with the capability to stimulate the heart (with pacing function), intramyocardial electrograms can be acquired from both the spontaneously beating and the paced heart. Figure 1 depicts typical examples of intramyocardial electrograms from the paced and the spontaneously beating heart, simultaneously recorded with the one-channel surface electrocardiograms. The pacing mode allows better standardization with regard to heart rate and supports signal processing by averaging $\left[{ }^{1}\right]$.

It should be taken into account that the stimulus typically is followed by a "blanking" period that also comprises the auto-shortening interval. During that blanking period the sensing channel of the pacemaker is inactivated and no signal is recorded. Auto-shortening means a process that is used for the acceleration of 


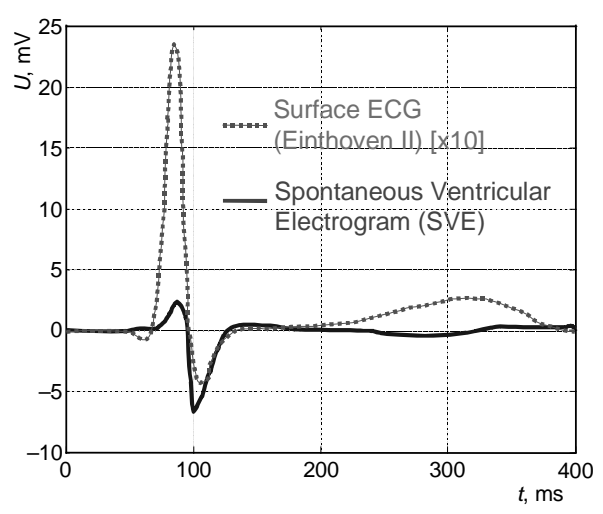

(a)

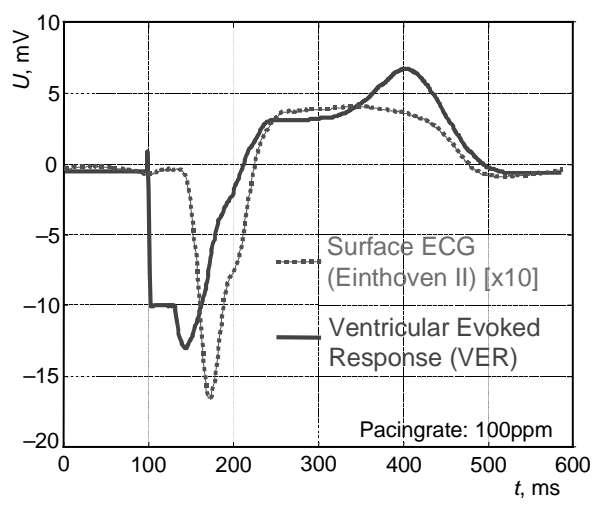

(b)

Fig. 1. Records of intramyocardial electrograms from the spontaneously beating (a) and the paced heart (b) in their correct timely relation with the surface electrocardiogram.

the re-establishment of the polarization potential across the electrode after the disturbance by the stimulus.

Fractally coated electrodes render possible the recording of broad-bandwidth signals with diagnostic quality since the record contains all diagnostically relevant details of the signal morphology $\left[{ }^{2}\right]$. Fractally coated electrodes offer additionally the possibility to employ the same electrode for the stimulation and the subsequent recording of the evoked response. Evoked responses reflect the process of spreading and regression of excitations originating from the site of stimulation. This methodological approach has been evaluated in different clinical studies. Those studies have mainly been concerned with rejection detection in heart transplant patients $\left[{ }^{3-6}\right]$. Figure 2 illustrates the changes in the morphology of intramyocardial electrograms from a paced heart in a heart transplant recipient during the post-operative days (POD).

On $\mathrm{POD}=7$ the heart showed neither rejection nor infection, on $\mathrm{POD}=28 \mathrm{a}$ clinically significant rejection was proved by endomyocardial biopsy, on POD = 128 a serious infection occurred, and on POD $=154$ a state without rejection or infection was reached again. It can be seen that these pathological events change significantly the morphology of the intramyocardial electrograms, and that the "healthy" state of the heart after recovery on POD $=154$ yields a quite comparable signal morphology with that of POD $=7$.

It has been found, however, that this methodological approach can also be used for assessing the hemodynamic performance of the heart, for example, to use it for patients with different kinds of cardiomyopathies $\left[{ }^{7-9}\right]$. The schematic in Fig. 3 depicts how intramyocardial electrograms can be recorded, subsequently transmitted via the internet and finally processed in a specialized service centre.

However, until now there are two distinct shortcomings of this promising approach. 


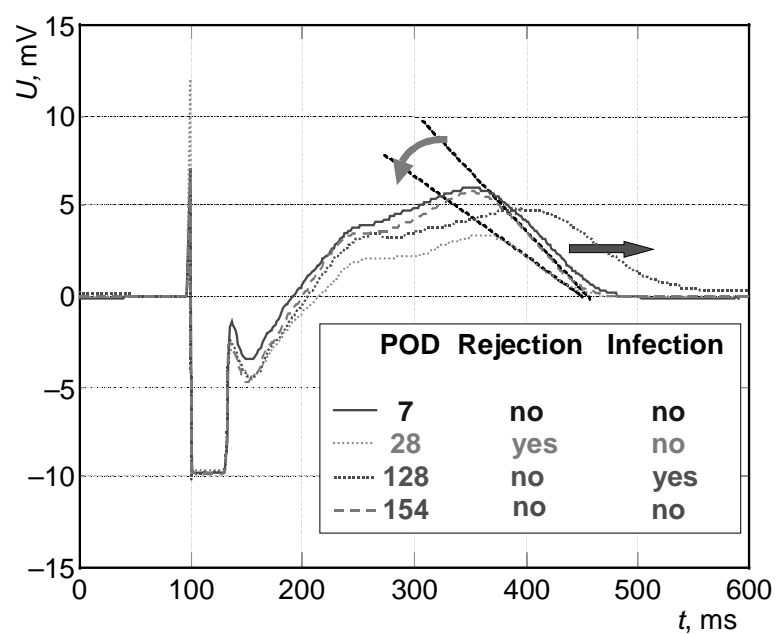

Fig. 2. Comparison of different records of intramyocardial electrograms from the same heart transplant patient with rejection at $\mathrm{POD}=28$ and infection at $\mathrm{POD}=128$.

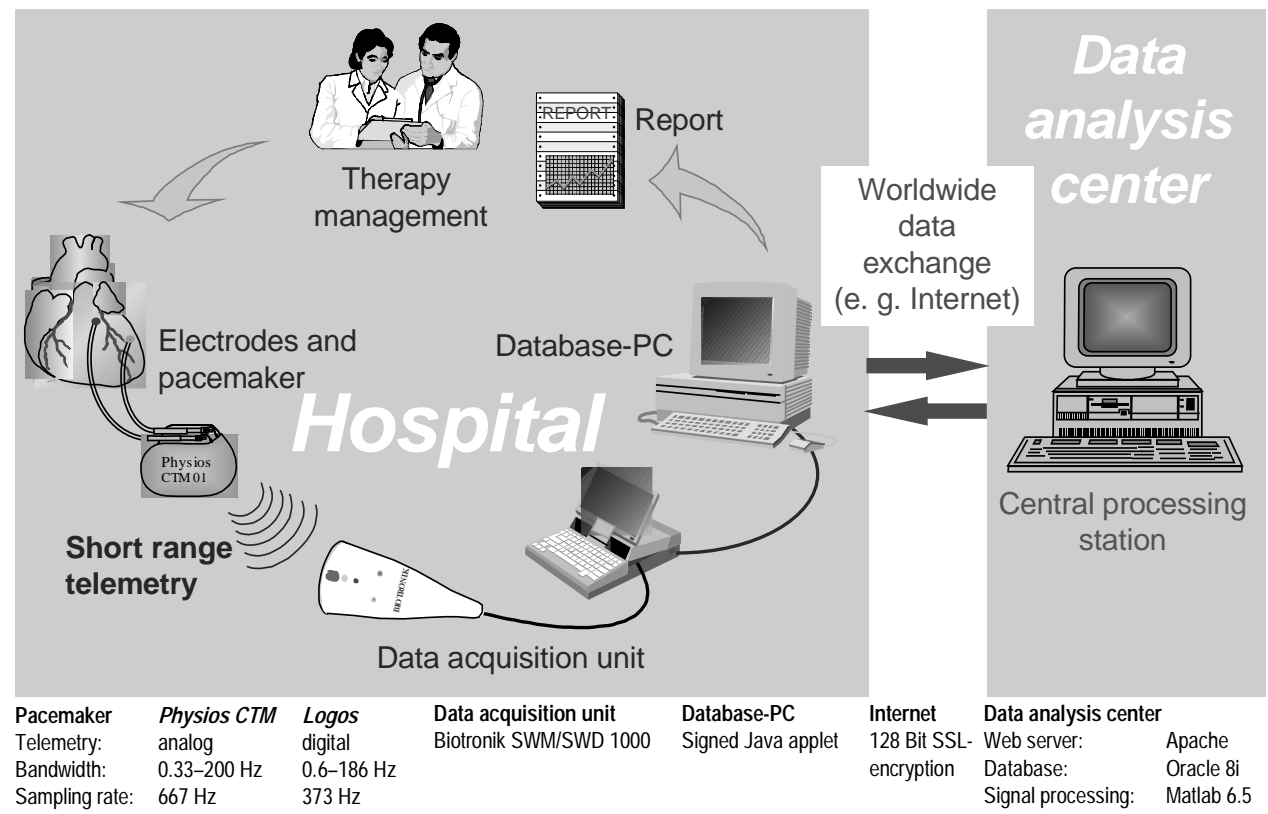

Fig. 3. Schematic for the recording of intramyocardial electrograms employing an implant with short-range telemetry, subsequent transmission via the internet and processing in a specialized service centre.

1. Due to insufficient understanding, the signal morphology can not be related with processes like excitation spreading and regression. The assignment of 
individual features like the anatomical geometry and size of the heart or the position of the recording electrode to certain details of the signal morphology is not possible. It is obvious, however, that the recording electrode can be considered as a distant observer of a summing potential that is representing all involved electrophysiological processes in the individual heart.

2. As a consequence, individual diagnosis based on signal evaluation is not feasible. For long-term monitoring, each patient has to be taken as his own reference. But such an individual reference can be set up only if the patient reaches a rather "normal" and stable condition. This requirement is not met during dynamic processes like the "ingrowing" of a transplanted heart into the receiver organism within the first and most critical post-transplant days, or in cases when the patient's condition is impairing rapidly.

The request therefore has been to develop a valid model for the heart with special regard of the electrophysiological processes and of the subsequent contraction. The model should additionally allow proper matching to individual anatomical geometries, if those are available, by imaging methods like ultrafast CT and NMR.

\section{METHOD}

\subsection{Ellipsoidal model}

As a first approach, a simple model has been realized in which the two ventricles are modelled by ellipsoidal shapes. Utilizing the finite element method (FEM), the total myocardial muscle mass has been dissected into 17829 cubes with an edge length of $2.5 \mathrm{~mm}$. Each cube can be assigned with "individual" electrical and mechanical properties. Thus the whole system is functioning like a cellular machine with regard to both the electrical and the mechanical behaviour. Electrical properties are the shape of the action potential, the (anisotropic) speed of excitation spreading, and the electrical resistivity. The mechanical properties are modelled by a spring-mass damping system that mimicks the contractile behaviour under proper consideration of the fibre direction. Each cube is in fixed mechanical connection with its neighbours during the contraction. The electrode is surrounded by a growing fibrotic capsule. Movements of the electrode together with the enclosed fibrotic capsule are caused by the forces that are exerted by the contracting myocardial cells or cubes.

Stimulation and recording can be made with the same electrode or with different ones. Recording is based on the summation of the potential at the electrode position. Only interfaces between volumes of different resistivity contribute to that potential $\left[{ }^{10}\right]$. Such interfaces are the epicardial surfaces of the free wall of the left and right ventricles, the whole endocardial surfaces of both ventricles, the plane comprising the four heart valves, and the border plane of the fibrotic capsule. The potential for each plane is transferred to an equivalent angular potential in accordance with the "solid angle theory" $\left[{ }^{11}\right]$. 
The front of the spreading excitation is followed by another front of the contraction. The time course of contraction mimicks the real contractile behaviour of cardiac cells. The most critical requests have been that the reduction in intraventricular blood volume must be in accordance with physiological values, and that the total muscle mass may not change during contraction.

This model allows in a simple way to change systematically certain parameters like the shape of the individual action potential or the position of the electrode, and to analyse the influence of these on the morphology of the recorded signal. The simulations have been executed with a $\mathrm{P} 4 / 3 \mathrm{GHz} \mathrm{PC}$. The program is mainly based on MATLAB. A single simulation run takes about $75 \mathrm{~h}$. This computing time can be reduced significantly by using more tailored software and data processing.

\subsection{Individually matched models}

First ultrafast CT images of the heart in enddiastolic and endsystolic situation have been acquired from one patient who was supplied with a telemetric pacemaker. A challenging problem was the appropriate computer-assisted segmentation since only a small volume of contrast medium can be administered in the patient. With adequate segmentation it is possible to reconstruct the individual 3D shape of the heart. This 3D reconstruction does not depict, however, the movement of individual cells or cubes from their enddiastolic to endsystolic position during contraction with the exception of the electrode. The electrode can be identified and used as a marker.

\section{RESULTS}

\subsection{Ellipsoidal model}

The most extended simulations have been performed with the ellipsoidal heart, which allows in a simple manner systematic variation of parameters with regard of the geometric dimensions and the muscle mass of the heart. Since the main interest has been the interpretation of evoked responses from the paced heart, the heart is not supplied with the special conduction system comprising the HIS-bundle, septal branches and Purkinje fibres. The implementation of that system is possible without any difficulty, but only with the spatial resolution that is determined by the volumes of the FEM cubes. Such an implementation is achieved simply by providing the cubes of the conduction system with respective electrical and mechanical properties.

Figure 4 shows the ellipsoidal heart model with two ventricles in its enddiastolic and endsystolic shape. The upper border plane with the valves is removed in order to allow a view into the intraventricular volumes which are separated by the septum. The electrode for stimulation and recording is placed in epimyocardial position at the right-ventricular free wall. This is the typical location for the 

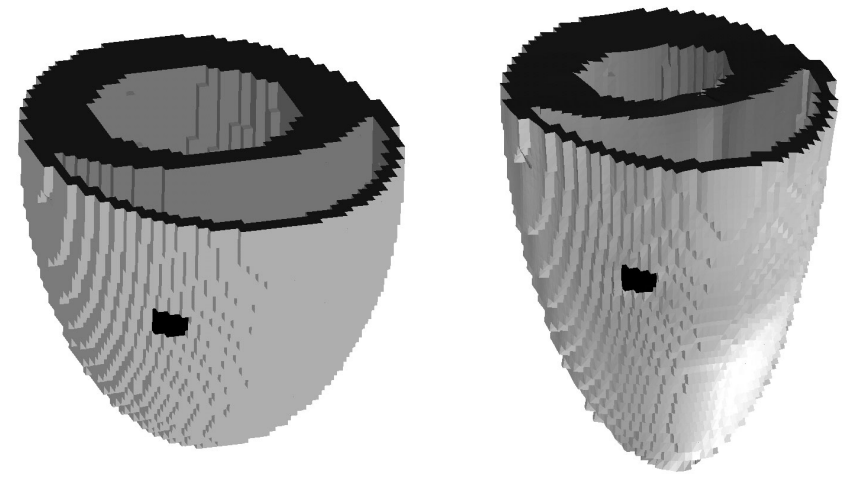

Fig. 4. Schematic illustration of the ellipsoidal heart model in enddiastolic and endsystolic shape with the electrode on the right-ventricular free wall.

electrode in heart transplant patients. The electrode is surrounded by the fibrotic capsule, which is growing during the first 6-8 weeks after fixation of the electrode. In the usual unipolar mode the pacemaker housing is assumed to be the reference electrode at a very "remote" distance. Under these conditions, the record represents the summing potential acquired at the place of the recording electrode.

The simulations have revealed excellent agreement in signal morphology with intramyocardial electrograms, recorded with epimyocardial electrodes in patients after heart transplantation. Since the employed telemetric pacemaker is actually a dual-channel device, electrodes could be placed not only in the right-ventricular epimyocardial position (the most preferred position for clinical reasons) but optionally additionally also in the left-ventricular epimyocardial position. Figure 5 shows a comparison of the two simulated intramyocardial electrograms for which only the position of the electrode has been changed from the right- to the leftventricular epimyocardial position. It is obvious that the signal morphology reveals some differences whereas the coarse shape is quite comparable.

Those summing potentials are composed of different components like the potentials originating from different interfaces between myocardial muscle on the one side and the blood in the ventricles, the fibrotic tissue of the capsule, or the plane between the ventricles and the atria with the four valves on the other side. Figure 6a illustrates different components that finally summarize in the intramyocardial electrogram as recorded with the electrode, placed in the right-ventricular free wall. It is obvious that under these circumstances the major contributions originate in the early phase from the fibrotic capsule and the right-ventricular endocardial layer, then from the epicardium, and at the end again from the right-ventricular endocardial layer. Compared with these components, the contributions originating from the plane between the atria and the ventricles and from the left-ventricular endocardial layer are of minor weight. The contribution of the left- ventricular free wall is small, although the muscle mass of that region is much larger than that of the right ventricle because it is more distant and seen under a smaller angle. 


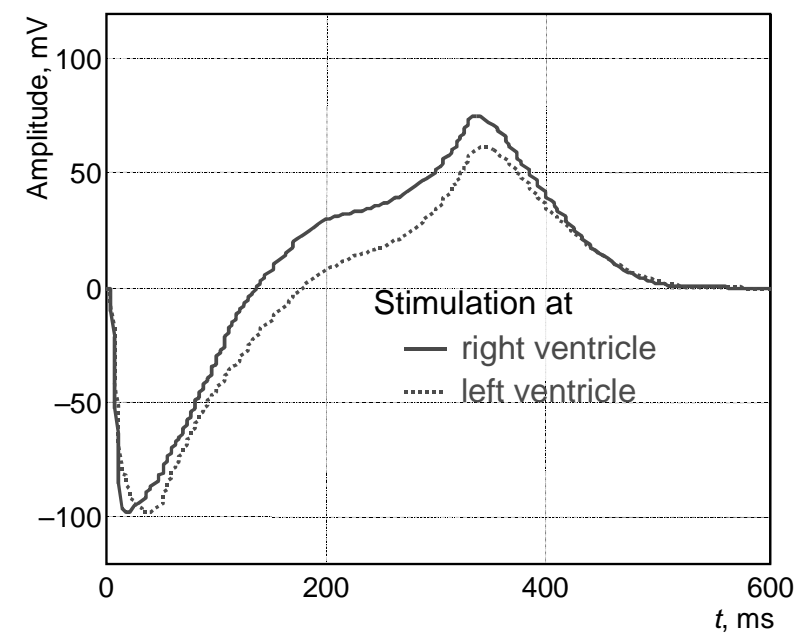

Fig. 5. Comparison of two simulated intramyocardial electrograms with the electrode in the rightand left-ventricular epimyocardial positions.

(a)

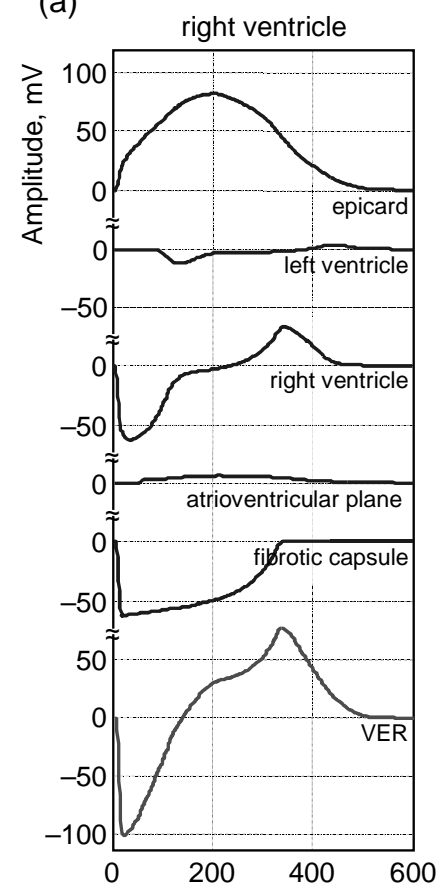

(b)

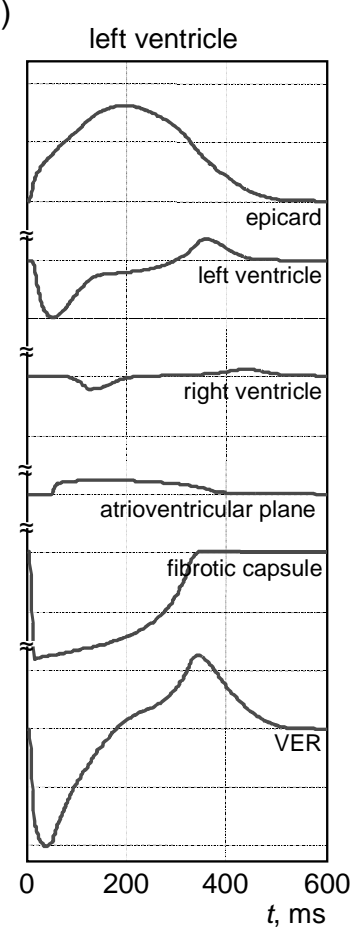

Fig. 6. Time course of different components that contribute to the summing myocardial electrogram after stimulation and recording at the right-ventricular free wall (a) and the left-ventricular free wall (b) in epicardial position. 


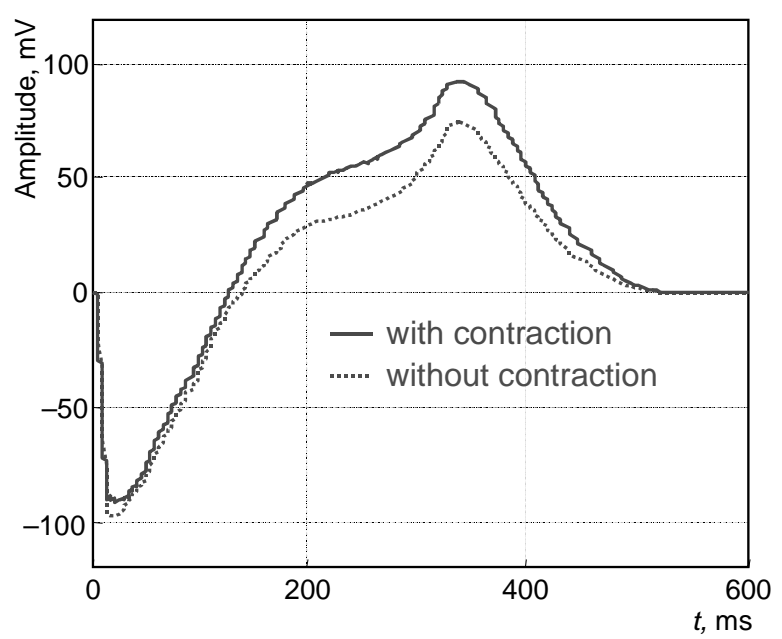

Fig. 7. Comparison of two intramyocardial electrogram simulations with and without contraction when the electrode is placed in the right-ventricular epicardial position.

Figure $6 \mathrm{~b}$ illustrates the comparable components with the electrode in the leftventricular epimyocardial position. In this case the early phase is even more dominated by the fibrotic capsule with a major contribution from the leftventricular endocardial layer, followed by the contribution from the epicardium. The contribution from the plane between the ventricles and atria is more enhanced than in the right-ventricular electrode position. The contribution from the right-ventricular endocardial layer is smaller than in Fig. 6a.

The simulation results shown in Fig. 6 have been obtained without simulating the contraction of the heart in order to reveal the effect of different electrode positions. In Fig. 7 the time courses of two simulations of the intramyocardial electrograms are compared with and without contraction when the electrode is placed in the right-ventricular epimyocardial position. The stroke volume has been assumed to be approximately $50 \mathrm{ml}$, i.e., near to real physiological values for adult persons under resting conditions. It is obvious that the two curves show remarkable deviations, mainly in the shape during the second half of the event when the reduction in intraventricular filling volume becomes effective. In a clinical study and by comparison with echocardiographic examinations it has been found that at least three parameters of the intramyocardial electrograms (the amplitude of the negative maximum VER_Ramp, the maximal slope between the negative and the positive maximum VER_Rslew, the amplitude of the positive maximum VER_Tamp) correlate significantly with the ejection fraction EF $\left.{ }^{7}\right]$. These findings confirm the results of the simulations.

\subsection{Individually matched models}

Only preliminary results are available from simulations accomplished with individually matched models. The ECG-triggered ultrafast CT images have been 


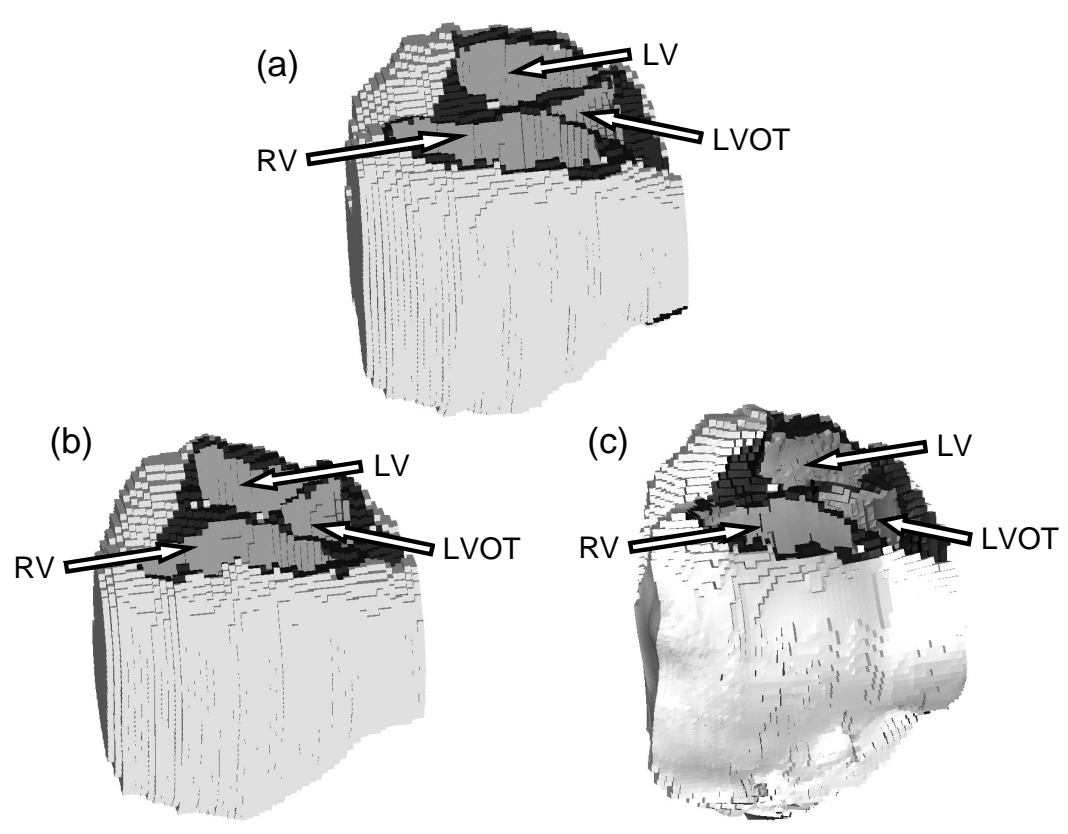

Fig. 8. Comparison of the 3D shape of the heart in enddiastolic (a) and endsystolic (b) situation of the heart in the patient and after model-based simulation (c); (LV - left ventricle, RV - right ventricle, LVOT - left ventricular outflow tract).

acquired from one heart transplant patient who is equipped with a telemetric pacemaker device. The segmentation problem has been solved so that the 3D data for the heart shape in enddiastolic and endsystolic situations could be calculated. The first approach has been started to transform the enddiastolic shape into the endsystolic shape by employing the FEM-based contraction model that was already used in the ellipsoidal model. The results are promising, however, further optimization is needed for perfect matching of the 3D model after contraction with that of the patient. Figure 8 gives an impression of the real and the model-based change in the 3D shape of the heart.

\section{DISCUSSION}

Model-based interpretation is not only an engineering challenge, but until now the only access to the extensive utilization of the diagnostic potential that will become available by the evaluation of intramyocardial electrograms from both the paced and the spontaneously beating heart for risk assessment and monitoring. The model that has been developed for that purpose allows a systematic analysis of all parameters, which might be relevant for proper consideration of individual factors and pathological impacts. 
Evaluation of the model has been based on the comparison of simulated intramyocardial electrograms with those acquired from patients after heart transplantation and with different kinds of cardiomyopathies, employing echocardiographic examinations and hemodynamic measurements by thermodilution during resting periods in different positions and during exercise tests. Until now no fundamental objection to the validity of the basic model structure with regard of its electrical and mechanical behaviour has been found. However, evaluation has to be continued, based on extensive simulation experiments and on comparison with clinical studies, before the promising potential for cardiac risk assessment and monitoring can be realized.

\section{REFERENCES}

1. Schreier, G., Kastner, P., Hutten, H., Schaldach, M., Gresser, B., Iberer, F., and Tscheliessnigg, K. H. Ventricular evoked responses versus spontaneous ventricular electrograms for long-term cardiac monitoring. Prog. Biomed. Res., 1996, 1, 77-83.

2. Schaldach, M., Hubmann, M., Weikl, A., and Hardt, R. Sputter-deposited TiN electrode coatings for superior sensing and pacing performance. PACE, 1990, 13, 1891-1895.

3. Auer, T., Schreier, G., Hutten, H., Kleinut, R., Wasler, A., Petutschnigg, B., Iberer, F., Tscheliessnigg, K. H., and Schaldach, M. Paced epimyocardial electrograms for noninvasive rejection monitoring after heart transplantation. J. Heart Lung Transplant., 1996, 15, $993-$ 998.

4. Bourge, R., Eisen, H., Hershberger, R., Keller, A., Radovancevic, B., Schreier, G., Kastner, B., Hutten, H., Wery, S., and Mehta, N. Noninvasive rejection monitoring of cardiac implants using high resolution intramyocardial electrograms - initial US multicenter experience. PACE, 1998, 21, 2338-2344.

5. Hutten, H., Schreier, G., Auer, T., Iberer, F., Tscheliessnigg, K. H., and Schaldach, M. Aufzeichnung und Analyse intramyokardialer Elektrogramme zur Überwachung auf Abstossung bei Herztransplantierten. Biomed. Technik, 1994, 39, Ergänzungsband, 276-277.

6. Hutten, H., Schreier, G., Kastner, P., Grasser, B., Iberer, F., and Tscheliessnigg, K. H. Der Herzschrittmacher als Brücke zum kardialen Telemonitoring. Biomed. Technik, 1996, 41, $158-165$.

7. Hribernigg, M., Ebner, E., Kraetschmer, H., Hutten, H., and Rauchegger, G. Correlation between electrophysiologic and hemodynamic parameters of the paced heart. In IFMBE Proc., Series 3, Part 1, EMBEC'02 (Hutten, H. and Krösl, P., eds.), 2002, 336-337.

8. Hutten, H., Kastner, P., Schreier, G., and Schaldach, M. Hemodynamic assessment by evaluation of intramyocardial electrograms. In Proc. 20th Annal International Conference IEEEEMBS, 1998, vol. 20, Part 1, 395-398.

9. Hutten, H. Telesurveillance of patients with cardiac risks. Eur. Surg., 2002, 34, 303-307.

10. Titomir, L. and Kneppo, P. Bioelectric and Biomagnetic Fields - Theory and Applications in Electrocardiology. CRC Press, Boca Raton, Florida, 1994.

11. Plonsey, R. and Barr, R. C. Bioelectricity - A Quantitative Approach. Plenum Press, New York, 1988. 


\title{
Mudelitel baseeruv intramüokardiaalsete elektrogrammide interpreteerimine kardiaalse riski hindamisel ja jälgimisel
}

\begin{abstract}
Helmut Hutten
Intramüokardiaalsed elektrogrammid, mida saadakse telemeetriliste võimalustega implanteeritud seadmete abil, on kardiaalse riski pikaajalisel hindamisel ja jälgimisel paljulubavad. Eelmainitud seadmete potentsiaali täielikumaks kasutamiseks on vaja uut lähenemist nende signaalide interpreteerimisele. Töös on välja töötatud mudel erutuse leviku ja sellele vastava südamelihase kontraktsiooni simuleerimiseks. See mudel võimaldab analüüsida oluliste parameetrite, sealhulgas stimulatsiooni ja registreerimise elektroodide paigutuse mõju. Mudelit saab kohandada patsiendi südame geomeetriale, kasutades näiteks kompuutertomograafia kujutist. Selline lähenemine aitab kasutada infot, mis sisaldub intramüokardiaalse elektrogrammi morfoloogias, kardiaalse riski seireks.
\end{abstract}

